\title{
Fontes de potássio para produção e qualidade de tomate cultivado em sistema orgânico em ambiente protegido
}

\author{
Potassium sources for production and quality of tomato grown in an organic system in a protected \\ environment
}

Fuentes de potasio para la producción y calidad de tomate cultivado en un sistema orgánico en un ambiente protegido

\section{Resumo}

O tomateiro é uma das plantas mais exigentes no elemento potássio $(\mathrm{K})$, sendo o correto fornecimento do nutriente decisivo para o sucesso da atividade. Na produção orgânica do fruto, as adubações potássicas são especialmente complexas. No Brasil, o cenário não ajuda o produtor de tomate orgânico, a maioria dos insumos certificados apresentam baixo teor ou solubilidade de K, e, em muitos casos, baixa resposta à adubação. O presente trabalho teve por objetivo avaliar a produtividade e qualidade de frutos de tomate italiano submetidos a adubação potássica com três fontes de uso liberado na agricultura orgânica. Os tratamentos foram constituídos por dois sulfatos de potássio certificados (Polivida e Allganic) e um resíduo orgânico da indústria de pó de café (película de café), nas doses de 500 e $700 \mathrm{~kg} \mathrm{ha}^{-1}$ de $\mathrm{K}_{2} \mathrm{O}$, totalmente no plantio ou dividido em plantio mais três coberturas. Foram avaliadas a taxa de sobrevivência das mudas, a produção (número e massa) e a qualidade (taxa de frutos ocos e cheios e sólidos solúveis totais) de frutos. Os resultados mostram ausência de diferença estatística entre os tratamentos tanto para produção como qualidade (taxa de frutos ocos, cheios e sólidos solúveis totais) dos frutos. No entanto, os tratamentos com película de café necessitaram de replantio de mudas nos primeiros 14 dias após o transplantio, elevando os custos de cultivo.

Palavras-chave: Solanum lycopersicum L.; Potássio em sistemas orgânicos; Cultivo protegido.

\begin{abstract}
Tomato is one of the most demanding agricultural crops in potassium $(\mathrm{K})$, and the correct supply of the nutrient is decisive for the success of the activity. In organic fruit production, potassium fertilization is especially complex. In Brazil, the scenario does not help the organic tomato producer, most certified inputs have low $\mathrm{K}$ content and solubility, and, in many cases, low response to fertilization. This study aimed to evaluate the productivity and quality of italian tomato fruits submitted to potassium fertilization with three sources of free use in organic agriculture. The treatments consisted of two certified potassium sulfates (Polivida and Allganic) and an organic residue from the coffee powder industry (coffee pellicle), in doses of 500 and $700 \mathrm{~kg} \mathrm{ha}^{-1}$ of $\mathrm{K}_{2} \mathrm{O}$, totally at planting or divided into planting plus three coverages. The seedling survival rate, production (number and mass) and quality (rate of hollow and full fruits and total soluble solids) of fruits were evaluated. The results show no statistical difference between treatments for both production and quality (rate of hollow, full and total soluble solids) of the fruits. However,
\end{abstract}


treatments with coffee pellicle required seedling replanting in the first 14 days after transplanting, increasing cultivation costs.

Keywords: Solanum lycopersicum L.; Potassium in organic systems; Protected cultivation.

\section{Resumen}

El tomate es uno de los cultivos agrícolas más exigentes en cuanto a potasio $(\mathrm{K})$, y el correcto aporte del nutriente es determinante para el éxito de la actividad. En la producción de frutas orgánicas, la fertilización con potasio es especialmente compleja. En Brasil, el escenario no ayuda al productor de tomate orgánico, la mayoría de los insumos certificados tienen bajo contenido de $\mathrm{K}$ y solubilidad y, en muchos casos, baja respuesta a la fertilización. Este estudio tuvo como objetivo evaluar la productividad y calidad de frutos de tomate italianos sometidos a fertilización potásica con tres fuentes de libre uso en agricultura orgánica. Los tratamientos consistieron en dos sulfatos de potasio certificados (Polivida y Allganic) y un residuo orgánico de la industria del café en polvo, en dosis de 500 y $700 \mathrm{~kg} \mathrm{ha}$ ${ }^{1}$ de $\mathrm{K}_{2} \mathrm{O}$, totalmente en plantación y dividido en plantación más tres coberturas. Se evaluó la tasa de supervivencia de las plántulas, la producción (número y masa) y la calidad (tasa de frutos huecos y llenos y sólidos solubles totales) de frutos. Los resultados no muestran diferencias estadísticas entre los tratamientos tanto para la producción como para la calidad (tasa de frutos huecos, llenos y sólidos solubles totales) de los frutos. Sin embargo, los tratamientos con película de café requirieron la resiembra de plántulas en los primeros 14 días después del trasplante, aumentando los costos de cultivo.

Palabras clave: Solanum lycopersicum L.; Potasio en sistemas orgânicos; Cultivo protegido.

\section{Introdução}

A produção de alimentos orgânicos é um dos setores do agronegócio mundial que mais cresce anualmente. No Brasil, os números de produção orgânica mostram avanço no número de produtores e área plantada. De 2012 a 2017 houve um crescimento de $28 \%$ no número de produtores cadastrados, chegando a mais de 17 mil produtores. Já as unidades de produção orgânicas cadastradas chegaram a 20.050 (Lira, 2018).

O país também se destaca na cultura do tomateiro, chegando ao posto de $10^{\circ}$ maior produtor de tomate, com uma produção de 3,9 milhões de toneladas e uma área cultivada de 54 mil ha, segundo dados da FAOSTAT (2019).

Para a produção de tomates orgânicos são necessários insumos de qualidade que proporcionem um manejo mais equilibrado da fertilidade do solo. Nesse sentido, fontes de potássio (K) de qualidade são o maior desafio encontrado, visto que as fontes registradas no Brasil para o cultivo orgânico são escassas e normalmente de baixa qualidade.

No tomateiro, o K é o nutriente mais extraído e influencia fortemente a produtividade (Minami \& Mello, 2017). Segundo Almeida (2017), em trabalho com tomate em cultivo orgânico, o consumo de K para produção de uma tonelada de frutos é de 2,9 kg, próximo do observado por Trani et al. (2015), em trabalho com tomate cultivado no sistema convencional, em que o consumo de K por tonelada de tomate produzida foi de 2,8 e 3,1 para os híbridos Gault e Pomerano, respectivamente.

As recomendações de adubação potássica levam em consideração primeiramente o teor de $\mathrm{K}$ trocável, indicado pela análise de solo, e posteriormente a produtividade esperada (Raij, 2017). Comumente é feito o parcelamento das adubações potássicas em adubação antes do plantio e adubações de coberturas, com objetivo de aumentar a eficiência de absorção do elemento, uma vez que é facilmente perdido por lixiviação (Partelli et al., 2014).

As doses de $\mathrm{K}_{2} \mathrm{O}$ recomendadas em publicações científicas e boletins técnicos de adubação costumam variar. Mueller et al. (2015) observaram maior produção total de tomate com doses de $\mathrm{K}_{2} \mathrm{O}$ a partir de $428 \mathrm{~kg} \mathrm{ha}^{-1}$ e maior produtividade de

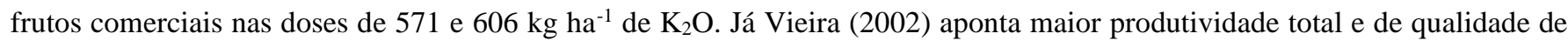
fruto de tomate quando as doses foram superiores a $600 \mathrm{~kg} \mathrm{ha}^{-1}$.

Existem trabalhos na literatura que avaliam eficácia de materiais orgânicos como fontes alternativas de K. Arruda et al. (2016) mostram as cinzas de biomassa florestal como uma alternativa interessante. Ramalho \& Pires (2010) apontam a casca de café com pergaminho, resíduo da indústria de pó de café, como excelente adubo potássico orgânico contendo teor de 4,3 $\mathrm{g} \mathrm{kg}^{-1} \mathrm{de} \mathrm{K}_{2} \mathrm{O}$ e Ferreira (2011a), por sua vez, sugere o uso da borra de café como fonte alternativa de potássio, entre outros macronutrientes. Já Fernandes et al. (2011) observaram acréscimo nos níveis de K no solo, de 243 para 260 mg dm-3, após 
adubação com $10 \mathrm{t} \mathrm{ha}^{-1}$ de torta de mamona.

No que diz respeito aos sulfatos de potássio certificados, estes apresentam maior teor de potássio que qualquer outro material na agricultura orgânica. São exemplos o Paulivida, com 50\% de $\mathrm{K}_{2} \mathrm{O}$ e 17\% de S (Paulifertil, 2021) e o Allganic, com $52 \%$ de $\mathrm{K}_{2} \mathrm{O}$ e $17 \%$ de $\mathrm{S}$ (Sqm-vitas, 2021).

É inegável a necessidade de procurar formas de produzir alimentos orgânicos em maior quantidade e qualidade para, assim, aumentar o acesso das pessoas a uma alimentação mais saudável. Quanto a relevância científica, esta se dá pelo fato de haver uma forte demanda por estudos de novas fontes para nutrição do tomateiro orgânico, sobretudo em adubação potássica, e a necessidade de testar a qualidade e viabilidade econômica de insumos já registrados para uso nesse sistema no Brasil.

Diante disso, o objetivo desse trabalho foi definir dentre três fontes de potássio qual oferece melhor resposta em produtividade e qualidade de frutos, assim como a melhor forma de aplicar o insumo.

\section{Metodologia}

A pesquisa de campo foi realizada na Fazenda Santa Terezinha do Rio Bonito em Itatinga, SP. A unidade de produção possui certificação orgânica concedida pela OIA Brasil e pertence ao grupo Rio Bonito Orgânicos. A estufa agrícola que recebeu o experimento é do tipo arco, com $3.780 \mathrm{~m}^{2}(105 \times 36 \mathrm{~m})$ de área total, apresenta pé direito de $5 \mathrm{~m}$, possui cobertura de filme de polietileno $(150 \mu \mathrm{m})$ e laterais com tela antiafídeo (50 mesh), sendo reservadas duas capelas, $504 \mathrm{~m}^{2}$ (14 x $36 \mathrm{~m}$ ), para realização do experimento.

Foram coletadas amostras de solo nas profundidades de 0 a 20 e 20 a $40 \mathrm{~cm}$, para análise química da área. Cada amostra foi composta por $30 \mathrm{sub}$ amostras retiradas ao acaso ao longo da estufa. Na sequência, as amostras foram enviadas ao Laboratório de Fertilidade de Solo do Instituto Agronômico de Campinas (IAC). Os resultados obtidos foram: 0-20cm: pH $\left(\mathrm{CaCl}_{2}\right)=6,6$; matéria orgânica $=31 \mathrm{~g} \mathrm{dm}^{-3} ; \mathrm{H}=9$ mmol $_{\mathrm{c}} \mathrm{dm}^{-3} ; \mathrm{P}=372 \mathrm{mg} \mathrm{dm}^{-3} ; \mathrm{K}=3 \mathrm{mmol}_{\mathrm{c}} \mathrm{dm}^{-3} ; \mathrm{Ca}=344 \mathrm{mmol}_{\mathrm{c}} \mathrm{dm}^{-3}$; $\mathrm{Mg}=22 \mathrm{mmol}_{\mathrm{c}} \mathrm{dm}^{-3} ;$ soma de bases $=371,9 \mathrm{mmol}_{\mathrm{c}} \mathrm{dm}^{-3} ; \mathrm{CTC}=380,9 \mathrm{mmol}_{\mathrm{c}} \mathrm{dm}^{-3}$; saturação de bases $(\mathrm{V})=98 \% ; 20-40 \mathrm{~cm}$ : $\mathrm{pH}\left(\mathrm{CaCl}_{2}\right)=6,9 ;$ matéria orgânica $=24 \mathrm{~g} \mathrm{dm}^{-3} ; \mathrm{H}=8$ mmol $_{\mathrm{c}} \mathrm{dm}^{-3} ; \mathrm{P}=228 \mathrm{mg} \mathrm{dm}^{-3} ; \mathrm{K}=1,3 \mathrm{mmol}_{\mathrm{c}} \mathrm{dm}^{-3} ; \mathrm{Ca}=226$ mmol $_{\mathrm{c}}$

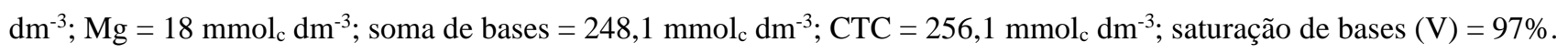

A alta fertilidade, CTC, P e Ca é resultado de 12 anos de cultivo orgânico, recebendo ao longo desse período grande aporte de matéria orgânica, corretivos (calcários) e fertilizantes fosfatados (como farinha de osso e fosfatos naturais).

O preparo do solo na área do experimento foi realizado dez dias antes do transplante das mudas. A adubação de plantio foi feita de maneira manual com composto do tipo bokashi, previamente fermentado, produzido na Fazenda, na dose de $7.619 \mathrm{~kg} \mathrm{ha}^{-1}$, que corresponde a 228,6 $\mathrm{kg} \mathrm{ha}^{-1}$ de $\mathrm{N}, 95,9 \mathrm{~kg} \mathrm{ha}^{-1}$ de $_{2} \mathrm{O}_{5}$ e 77,77 kg ha-1 de $\mathrm{K}_{2} \mathrm{O}$. Na sequência foi feita aplicação dos tratamentos e posteriormente os adubos foram incorporados ao solo, até uma profundidade de $20 \mathrm{~cm}$, com um micro trator.

Os canteiros foram construídos nas dimensões de $32 \mathrm{~m}$ de comprimento, $1 \mathrm{~m}$ de largura e $0,20 \mathrm{~m}$ de altura e foram cobertos com "mulching" plástico, branco e preto, de $17 \mu \mathrm{m}$ de espessura.

O delineamento experimental utilizado foi de blocos ao acaso, com 14 tratamentos e seis repetições, totalizando 84 parcelas. Os tratamentos foram formados por variações de doses $\left(500 \mathrm{~kg} \mathrm{ha}^{-1} \mathrm{e} 700 \mathrm{~kg} \mathrm{ha}^{-1}\right.$ ), épocas de aplicação (somente no plantio - P - e no plantio e mais três coberturas - C - aos 28, 49 e 70 dias após o transplante - DAT) e combinações de três insumos: o sulfato de potássio Allganic da empresa SQM (52\% de $\mathrm{K}_{2} \mathrm{O}$ e $17 \%$ de S), o sulfato de potássio Paulivida da empresa Paulifertil (50\% de $\mathrm{K}_{2} \mathrm{O}$ e $17 \%$ de S) e o resíduo orgânico da indústria do café conhecido como película de café (fino tecido vegetal que se localiza entre as sementes do fruto de café e o endocarpo, também chamado de pergaminho), resultando nos seguintes tratamentos: T1: $\mathrm{P}=$ Paulivida $\left(500 \mathrm{~kg} \mathrm{ha}^{-1}\right)+\mathrm{C}=0$; T2: $\mathrm{P}=$ Paulivida $\left(300 \mathrm{~kg} \mathrm{ha}^{-1}\right)+\mathrm{C}=$ Paulivida $(3 \times 66,6$ $\left.\mathrm{kg} \mathrm{ha}^{-1}\right) ; \mathrm{T} 3: \mathrm{P}=$ Paulivida $\left(300 \mathrm{~kg} \mathrm{ha}^{-1}\right)+\mathrm{C}=$ Allganic $\left(3 \times 66,6 \mathrm{~kg} \mathrm{ha}^{-1}\right) ; \mathrm{T} 4: \mathrm{P}=$ Allganic $\left(500 \mathrm{~kg} \mathrm{ha}^{-1}\right)+\mathrm{C}=0$; T5: $\mathrm{P}=$ 
Allganic $\left(300 \mathrm{~kg} \mathrm{ha}^{-1}\right)+\mathrm{C}=$ Allganic $\left(3 \times 66,6 \mathrm{~kg} \mathrm{ha}^{-1}\right) ; \mathrm{T} 6: \mathrm{P}=$ Allganic $\left(300 \mathrm{~kg} \mathrm{ha}^{-1}\right)+\mathrm{C}=$ Paulivida $\left(3 \times\right.$ x 66,6 kg ha- $\left.{ }^{-1}\right) ; \mathrm{T} 7$ : $\mathrm{P}=$ Película de café (500 kg ha-1) + C = 0; T8: $\mathrm{P}=$ Película de café (300 kg ha-1) + C = Paulivida (3 x 66,6 kg ha-1); T9: $\mathrm{P}=$ Película de café $\left(300 \mathrm{~kg} \mathrm{ha}^{-1}\right)+\mathrm{C}=$ Paulivida $\left(3 \times 66,6 \mathrm{~kg} \mathrm{ha}^{-1}\right)$; T10: $\mathrm{P}=0+\mathrm{C}=0$; T11: $\mathrm{P}=$ Paulivida $\left(500 \mathrm{~kg} \mathrm{ha}^{-1}\right) \mathrm{e}$ Allganic $\left(200 \mathrm{~kg} \mathrm{ha}^{-1}\right)+\mathrm{C}=0$; T12: $\mathrm{P}=$ Paulivida $\left(200 \mathrm{~kg} \mathrm{ha}^{-1}\right)$ e Allganic $\left(500 \mathrm{~kg} \mathrm{ha}^{-1}\right)+\mathrm{C}=0$; T13: $\mathrm{P}=$ Película de café $\left(500 \mathrm{~kg} \mathrm{ha}^{-1}\right)$ e Allganic $\left(200 \mathrm{~kg} \mathrm{ha}^{-1}\right)+\mathrm{C}=0 ; \mathrm{T} 14: \mathrm{P}=$ Paulivida $\left(200 \mathrm{~kg} \mathrm{ha}^{-1}\right)$ e Película de café $\left(500 \mathrm{~kg} \mathrm{ha}^{-1}\right)+\mathrm{C}=0$.

Não foi possível adicionar um tratamento contendo uma fonte de potássio solúvel (como $\mathrm{KCl}$ ) devido ao fato da propriedade ser certificada orgânica e o uso desses insumos ser proibido. Durante o ensaio houve a necessidade de uma adubação de cobertura (aos 21 DAT) com adubo orgânico Fertiplus, NPK 04-03-03, na dose de $50 \mathrm{~g}_{\text {planta }}{ }^{-1}$ para aumentar o

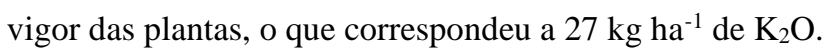

O híbrido de tomate italiano que foi utilizado como enxerto no experimento é o Colt da empresa H.M. Clause e o porta-enxerto foi o 'Green Power' da empresa Takii Seeds. A enxertia foi realizada pelo método de garfagem tipo fenda cheia. A semeadura foi feita em 28/09/2020 e o transplante em 19/11/2020. As plantas foram cultivadas com duas hastes e conduzidas em fitilho até terem cinco cachos por haste, quando foi realizada a desbrota apical das hastes ("capação"), aos 45 DAT.

Após o transplante, foi feita uma avaliação da mortalidade das mudas aos 14 DAT, com os resultados expressos em porcentagem (\%). Após essa avaliação, fez-se o replantio das mudas para completar as parcelas.

As colheitas iniciaram no dia 14/01/2021 e finalizaram em 17/02/2021, sendo realizadas duas colheitas por semana. A produção por planta $(\mathrm{kg})$ foi calculada através da razão da massa total dos frutos colhidos na parcela pelo número de plantas da parcela. O número de frutos por planta foi calculado através da razão do número total de frutos colhidos na parcela pelo número de plantas da parcela. A massa média de frutos $\left(\mathrm{g}_{\text {fruto }}{ }^{-1}\right)$ foi calculada pela razão da massa total dos frutos colhidos pelo número total de frutos colhidos na parcela. Também foram avaliados o enchimento de frutos e sólidos solúveis totais. Em cada colheita eram avaliados três frutos por parcela, totalizando 1.134 frutos. As avaliações de enchimento foram feitas de maneira visual, mediante um corte transversal na região mediana dos frutos. Os frutos foram classificados em cheios, levemente ocos e ocos (Figura 1). Os dados foram apresentados em porcentagem (\%) do total de frutos amostrados.

Os dados foram submetidos à análise de variância utilizando-se o software SISVAR (Ferreira, 2011b) e, quando houve diferença, as médias foram agrupadas pelo teste de teste Scott Knott a 5\% de probabilidade. Para as características mortalidade de mudas após o transplante, porcentagem de frutos ocos, pouco ocos e cheios, os dados foram analisados com a opção de transformação Raiz quadrada de $\mathrm{Y}+1,0[(\mathrm{SQRT}(\mathrm{Y}+1,0)]$.

Figura 1. Da esquerda para direita: frutos cheios, pouco oco e ocos.

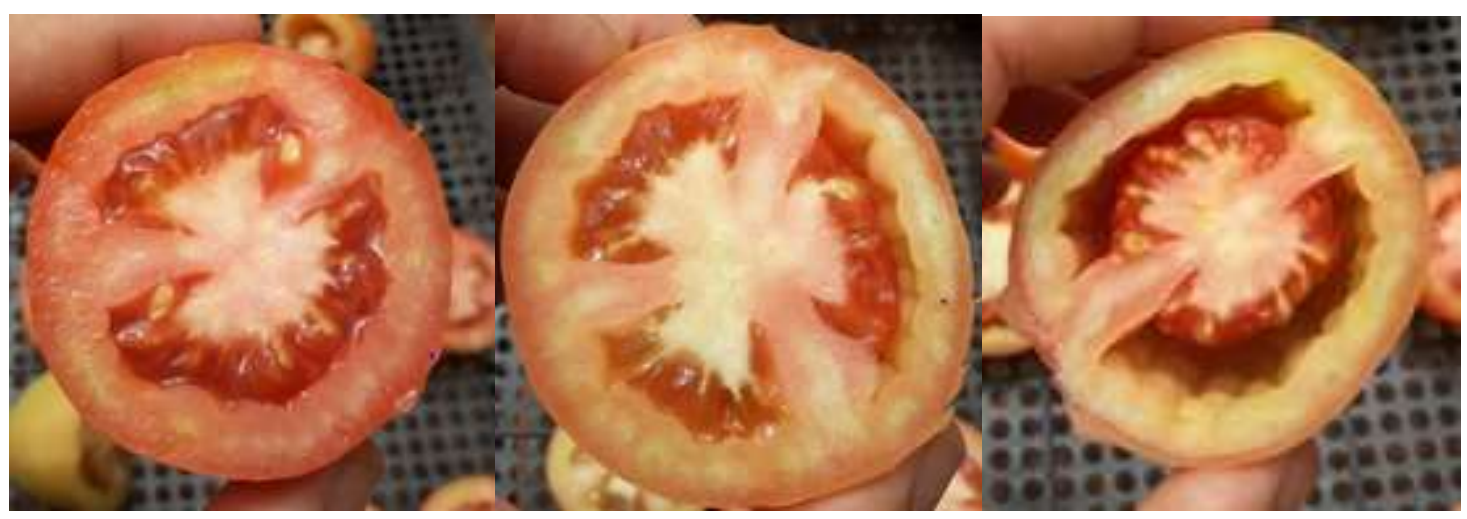

Fonte: Autores. 


\section{Resultados e Discussão}

Apenas para a característica mortalidade de mudas após o transplante o fator tratamentos foi significativo pelo teste $\mathrm{F}$ (Tabela 1). Para as demais características (produção por planta, quantidade de frutos por planta, massa média de fruto, teor de sólidos solúveis, porcentagem de frutos ocos, pouco ocos e cheios) o fator tratamentos não foi significativo pelo teste $\mathrm{F}$ a $5 \%$ de probabilidade.

Tabela 1. Quadrados médios, coeficiente de variação e média geral obtidos nas análises de variância para as características mortalidade de mudas $(\mathrm{M})$, produção por planta $(\mathrm{P})$, quantidade de frutos por planta $(\mathrm{F})$, massa média de fruto $(\mathrm{MF})$, porcentagem de frutos ocos $(\mathrm{O})$, pouco ocos $(\mathrm{PO})$ e cheios $(\mathrm{C})$ e sólidos solúveis totais do fruto (SST) em função de adubação orgânica à base de potássio em tomate.

\begin{tabular}{lcccccccc}
\hline $\begin{array}{l}\text { Fator de } \\
\text { variação }\end{array}$ & $\mathrm{M}^{1}$ & $\mathrm{P}$ & $\mathrm{F}$ & $\mathrm{MF}$ & $\mathrm{O}^{1}$ & $\mathrm{PO}^{1}$ & $\mathrm{C}^{1}$ & $\mathrm{SST}$ \\
\hline Tratamentos & $20,9^{*}$ & $0,51^{\mathrm{ns}}$ & $41,6^{\mathrm{ns}}$ & $14,3^{\mathrm{ns}}$ & $2,61^{\mathrm{ns}}$ & $1,43^{\mathrm{ns}}$ & $2,36^{\mathrm{ns}}$ & $0,048^{\mathrm{ns}}$ \\
Repetição & $18,8^{\mathrm{ns}}$ & $0,90^{\mathrm{ns}}$ & $81,4^{\mathrm{ns}}$ & $40,5^{\mathrm{ns}}$ & $1,10^{\mathrm{ns}}$ & $2,62^{\mathrm{ns}}$ & $1,07^{\mathrm{ns}}$ & $0,108^{\mathrm{ns}}$ \\
Erro & 7,1 & 0,60 & 51,6 & 25,7 & 1,59 & 1,37 & 2,17 & 0,055 \\
\hline CV $(\%)$ & 91,8 & 16,9 & 15,5 & 5,1 & 19,6 & 24,3 & 25,6 & 8,0 \\
\hline Média Geral & 18,2 & 4,6 & 46,2 & 99,3 & 42,2 & 23,5 & 34,3 & 2,9 \\
\hline
\end{tabular}

*= significativo pelo teste $\mathrm{F}$ a $5 \%$ de probabilidade

${ }^{\mathrm{ns}}=$ não significativo pelo teste $\mathrm{F}$ a $5 \%$ de probabilidade

${ }^{1}$ Opção de transformação: Raiz quadrada de $\mathrm{Y}+1,0$ [SQRT $\left.(\mathrm{Y}+1,0)\right]$

Fonte: Autores.

Houve diferença entre os tratamentos na avaliação de mortalidade de mudas após o transplante, sendo que os tratamentos T7, T13 e T14 (com película de café e película de café mais sulfatos) apresentaram maior mortalidade de mudas (Tabela 2), sendo necessário uma operação de replantio, acarretando aumento no custo de produção.

Os tratamentos contendo apenas os sulfatos de potássio (Paulivida e Allganic) a mortalidade foi baixa. No caso da utilização da película de café, a mortalidade foi elevada apenas quando se utilizou a maior dose (500 kg ha-1), pois na menor dose (300 kg ha-1) (T8 e T9) não diferiu da testemunha nem dos sulfatos. A provável causa da morte de mudas após o transplante com a utilização da película de café pode ser o fato deste material não estar totalmente fermentado, provocando aquecimento do solo próximo às raízes e morte destas. Na menor dose (300 kg ha-1) (T8 e T9), apesar de ter ocorrido mortes, não foi significativamente diferente da testemunha.

A necessidade de replantio gera maior gasto, tanto com as novas mudas como pela mão de obra necessária para a realização desta operação. Estima-se um custo de aproximadamente R \$ 4,50 (cerca de U\$ 1.00 pela cotação na época) por muda. Portanto, para uma mortalidade de 50,0\% a 69,5\% (tratamentos T7, T13 e T14), estima-se um custo a mais de R\$ 2.250,00 a $\mathrm{R} \$ 3.105,00$ para cada mil mudas plantadas, para repor as perdas, sem considerar a mão de obra para realizar o replantio. 
Tabela 2. Médias para produção por planta (P), quantidade de frutos por planta (F), massa média de fruto (MF), porcentagem de frutos ocos $(\mathrm{O})$, frutos pouco ocos (PO), frutos cheios (C), sólidos solúveis totais do fruto (SST) e mortalidade de mudas (M) em função de adubação orgânica à base de potássio em tomate.

\begin{tabular}{|c|c|c|c|c|c|c|c|c|}
\hline Tratamentos* & $\begin{array}{c}\mathrm{P} \\
\mathrm{kg} \cdot \text { planta }^{-1} \\
\end{array}$ & $\begin{array}{c}\mathrm{F} \\
\text { fruto.planta }^{-1} \\
\end{array}$ & $\begin{array}{c}\text { MF } \\
\text { g.fruto } \\
\text { g. }\end{array}$ & $\begin{array}{l}\mathrm{O}^{1} \\
\% \\
\end{array}$ & $\begin{array}{l}\mathrm{PO}^{1} \\
\% \\
\end{array}$ & $\%$ & $\begin{array}{r}\text { SST } \\
{ }^{\circ} \text { Brix } \\
\end{array}$ & $\begin{array}{l}\mathrm{M}^{1} \\
\%\end{array}$ \\
\hline 1 & $4,57 \mathrm{a}$ & $45,65 \mathrm{a}$ & $100,54 \mathrm{a}$ & $40,00 \mathrm{a}$ & $28,00 \mathrm{a}$ & $32,00 \mathrm{a}$ & $2,92 \mathrm{a}$ & $9,50 \mathrm{~b}$ \\
\hline 2 & $4,72 \mathrm{a}$ & $46,78 \mathrm{a}$ & $100,91 \mathrm{a}$ & $64,50 \mathrm{a}$ & $17,25 \mathrm{a}$ & $18,25 \mathrm{a}$ & $2,98 \mathrm{a}$ & $2,50 \mathrm{~b}$ \\
\hline 3 & $4,43 \mathrm{a}$ & $44,65 \mathrm{a}$ & $99,40 \mathrm{a}$ & $44,75 \mathrm{a}$ & $19,50 \mathrm{a}$ & $35,75 \mathrm{a}$ & $2,95 \mathrm{a}$ & $0,00 \mathrm{~b}$ \\
\hline 4 & $4,65 \mathrm{a}$ & $47,25 \mathrm{a}$ & $98,32 \mathrm{a}$ & $35,50 \mathrm{a}$ & $22,00 \mathrm{a}$ & $42,50 \mathrm{a}$ & $2,86 \mathrm{a}$ & $0,00 \mathrm{~b}$ \\
\hline 5 & $4,44 \mathrm{a}$ & $45,00 \mathrm{a}$ & 98,78 a & $45,75 \mathrm{a}$ & $21,75 \mathrm{a}$ & $32,75 \mathrm{a}$ & $2,78 \mathrm{a}$ & $5,50 \mathrm{~b}$ \\
\hline 6 & $5,22 \mathrm{a}$ & $50,90 \mathrm{a}$ & $102,77 \mathrm{a}$ & $29,00 \mathrm{a}$ & $19,25 \mathrm{a}$ & $52,00 \mathrm{a}$ & $3,19 \mathrm{a}$ & $16,50 \mathrm{~b}$ \\
\hline 7 & $3,81 \mathrm{a}$ & $39,73 \mathrm{a}$ & 96,46 a & $56,25 \mathrm{a}$ & $15,50 \mathrm{a}$ & $28,50 \mathrm{a}$ & $2,89 \mathrm{a}$ & $69,50 \mathrm{a}$ \\
\hline 8 & $5,26 \mathrm{a}$ & $52,40 \mathrm{a}$ & 99,97 a & $36,00 \mathrm{a}$ & $27,50 \mathrm{a}$ & 36,75 a & $3,04 \mathrm{a}$ & $11,00 \mathrm{~b}$ \\
\hline 9 & $4,35 \mathrm{a}$ & $42,55 \mathrm{a}$ & $102,32 \mathrm{a}$ & $39,25 \mathrm{a}$ & $26,25 \mathrm{a}$ & 34,75 a & $2,84 \mathrm{a}$ & $27,75 \mathrm{~b}$ \\
\hline 10 & $4,72 \mathrm{a}$ & $48,50 \mathrm{a}$ & 96,97 a & $49,25 \mathrm{a}$ & $19,75 \mathrm{a}$ & 30,75 a & $2,93 \mathrm{a}$ & $0,00 \mathrm{~b}$ \\
\hline 11 & $4,69 \mathrm{a}$ & $47,05 \mathrm{a}$ & $99,00 \mathrm{a}$ & $51,25 \mathrm{a}$ & $19,50 \mathrm{a}$ & $29,25 \mathrm{a}$ & $2,99 \mathrm{a}$ & $0,00 \mathrm{~b}$ \\
\hline 12 & $4,63 \mathrm{a}$ & $47,18 \mathrm{a}$ & $98,29 \mathrm{a}$ & $35,00 \mathrm{a}$ & $29,25 \mathrm{a}$ & $36,00 \mathrm{a}$ & $2,76 \mathrm{a}$ & $0,00 \mathrm{~b}$ \\
\hline 13 & $4,37 \mathrm{a}$ & $44,63 \mathrm{a}$ & $97,19 \mathrm{a}$ & $34,00 \mathrm{a}$ & $39,25 \mathrm{a}$ & $26,50 \mathrm{a}$ & $2,85 \mathrm{a}$ & $62,50 \mathrm{a}$ \\
\hline 14 & $4,42 \mathrm{a}$ & $44,10 \mathrm{a}$ & $99,91 \mathrm{a}$ & $30,75 \mathrm{a}$ & $24,25 \mathrm{a}$ & $45,00 \mathrm{a}$ & $2,93 \mathrm{a}$ & $50,00 \mathrm{a}$ \\
\hline $\mathrm{F}_{\text {tratamento }}$ & $0,603^{\mathrm{ns}}$ & $0,650^{\mathrm{ns}}$ & $0,874^{\mathrm{ns}}$ & $0,116^{\mathrm{ns}}$ & $0,430^{\mathrm{ns}}$ & $0,400^{\mathrm{ns}}$ & $0,576^{\mathrm{ns}}$ & $0,005 *$ \\
\hline
\end{tabular}

Médias seguidas por letras diferentes na coluna diferem pelo teste de Scott Knott $(\mathrm{p}<0,05) ;{ }^{1}$ - Dados originais, porém transformados por raiz quadrada de $\mathrm{Y}+1,0[\mathrm{SQRT}(\mathrm{Y}+1,0)]$ para a análise de variância; * - significativo a 5\% de probabilidade; ns - não significativo.

* T1: $\mathrm{P}=$ Paulivida $\left(500 \mathrm{~kg} \mathrm{ha}^{-1}\right)+\mathrm{C}=0$; T2: $\mathrm{P}=$ Paulivida $\left(300 \mathrm{~kg} \mathrm{ha}^{-1}\right)+\mathrm{C}=$ Paulivida $\left(3 \times 66,6 \mathrm{~kg} \mathrm{ha}^{-1}\right) ; \mathrm{T} 3: \mathrm{P}=\mathrm{Paulivida}(300 \mathrm{~kg}$ ha $\left.{ }^{1}\right)+\mathrm{C}=$ Allganic $\left(3 \times 66,6 \mathrm{~kg} \mathrm{ha}^{-1}\right) ; \mathrm{T} 4: \mathrm{P}=$ Allganic $\left(500 \mathrm{~kg} \mathrm{ha}^{-1}\right)+\mathrm{C}=0$; T5: $\mathrm{P}=$ Allganic $\left(300 \mathrm{~kg} \mathrm{ha}^{-1}\right)+\mathrm{C}=$ Allganic $(3 \times 66,6 \mathrm{~kg} \mathrm{ha}$ $\left.{ }^{1}\right)$; T6: $\mathrm{P}=$ Allganic $\left(300 \mathrm{~kg} \mathrm{ha}^{-1}\right)+\mathrm{C}=$ Paulivida $\left(3 \times 66,6 \mathrm{~kg} \mathrm{ha}^{-1}\right) ; \mathrm{T} 7: \mathrm{P}=$ Película de café $\left(500 \mathrm{~kg} \mathrm{ha}^{-1}\right)+\mathrm{C}=0$; T8: $\mathrm{P}=\mathrm{Película} \mathrm{de}$ café $\left(300 \mathrm{~kg} \mathrm{ha}^{-1}\right)+\mathrm{C}=$ Paulivida $\left(3 \times 66,6 \mathrm{~kg} \mathrm{ha}^{-1}\right) ; \mathrm{T} 9: \mathrm{P}=$ Película de café $\left(300 \mathrm{~kg} \mathrm{ha}^{-1}\right)+\mathrm{C}=$ Paulivida $\left(3 \times 66,6 \mathrm{~kg}\right.$ ha $\left.{ }^{-1}\right) ; \mathrm{T} 10: \mathrm{P}=0$ + $\mathrm{C}=0$; T11: $\mathrm{P}=$ Paulivida $\left(500 \mathrm{~kg} \mathrm{ha}^{-1}\right)$ e Allganic $\left(200 \mathrm{~kg} \mathrm{ha}^{-1}\right)+\mathrm{C}=0 ; \mathrm{T} 12: \mathrm{P}=$ Paulivida $\left(200 \mathrm{~kg} \mathrm{ha}^{-1}\right)$ e Allganic $\left(500 \mathrm{~kg} \mathrm{ha}^{-1}\right)+\mathrm{C}=0$; T13: $\mathrm{P}=$ Película de café $\left(500 \mathrm{~kg} \mathrm{ha}^{-1}\right)$ e Allganic $\left(200 \mathrm{~kg} \mathrm{ha}^{-1}\right)+\mathrm{C}=0$; T14: $\mathrm{P}=$ Paulivida $\left(200 \mathrm{~kg} \mathrm{ha}^{-1}\right)$ e Película de café $\left(500 \mathrm{~kg}\right.$ ha $\left.{ }^{-1}\right)+$ $\mathrm{C}=0$.

Fonte: Autores.

Para a produção de frutos por planta, não houve diferença tanto para a massa como para número de frutos, com médias de 4,6 kg e 46,2 frutos por planta (Tabelas 1 e 2).

A produção total de frutos de tomate italiano no experimento foi, em média, de $7,67 \mathrm{~kg} \mathrm{~m}^{-2}$. Esse valor é considerado normal, comparado à média histórica de produção da fazenda. Portanto, nem a ausência de potássio (testemunha, T10), nem as maiores doses $\left(700 \mathrm{~kg} \mathrm{ha}^{-1}\right)$, independentemente da fonte e do momento de aplicação (plantio e/ou cobertura), afetaram a produção de frutos de tomate nas condições desta pesquisa.

$\mathrm{Na}$ ausência de análise química das folhas e dos frutos, assim como do solo ao final do experimento (não realizadas pelo elevado custo de se fazer em todas as parcelas experimentais), pode-se pensar em algumas hipóteses.

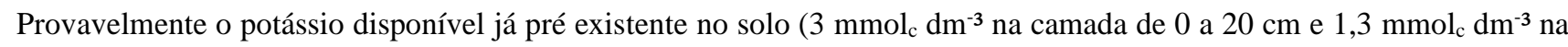
camada de 20 a $40 \mathrm{~cm}$ ), mais a matéria orgânica no solo, $31 \mathrm{mg} \mathrm{dm}^{-3}$ na camada de 0 a $20 \mathrm{~cm}$ e $24 \mathrm{mg} \mathrm{dm}^{-3}$ na camada de 20 a $40 \mathrm{~cm}$, mais o aplicado na adubação de base com bokashi e em cobertura com o adubo orgânico Fertiplus (4-3-3), pode ter sido suficiente para suprir as necessidades da planta. Em uma futura repetição do ensaio, podemos diminuir a interferência de outros fertilizantes no suprimento de K, uma vez que a multinacional ILSA, recentemente, registrou para o mercado orgânico brasileiro uma fonte de nitrogênio natural livre de outros nutrientes, o ILSADRIP FORTE com 9\% de N solúvel em água. 
Apesar dos adubos orgânicos e da matéria orgânica do solo não apresentarem os nutrientes prontamente disponíveis às plantas, o potássio costuma ser o primeiro nutriente a ser disponibilizado durante o processo de mineralização da matéria orgânica, pois a maior parte do potássio não faz parte da composição de substâncias complexas, encontrando-se na forma iônica $\left(\mathrm{K}^{+}\right)$, atuando como regulador da pressão osmótica das células e como ativador enzimático (Magro et al., 2010, 2015; Souza \& Resende, 2012). Desta maneira, o potássio na forma orgânica é quase tão disponível às plantas como em adubos inorgânicos, conforme descrito por Ernani et al. (2007) e Magro et al. (2010). A disponibilização do potássio que se encontra em materiais orgânicos no solo é ainda mais rápida sob condições de alta temperatura e na presença de elevada população de microrganismos benéficos (Monsalve et al., 2017), como os encontrados no bokashi que foi utilizado.

Isto poderia ser comprovado se tivessem sido feitas as análises químicas. Provavelmente o solo no tratamento testemunha deve ter tido o seu teor de $\mathrm{K}$ e de matéria orgânica reduzidos o que pode comprometer futuros plantios na mesma área, visto que grande quantidade de nutrientes é exportada com as colheitas dos frutos e devem ser restituídos com adubação. Almeida (2017), pesquisando curva de absorção de nutrientes em tomateiro sob cultivo orgânico, relatou que para cada tonelada de fruto colhido, 2,8 kg de K são exportados com a colheita. Considerando-se a produtividade média de 7,67 $\mathrm{kg} \mathrm{m}^{-2}\left(76,7 \mathrm{t} \mathrm{ha}^{-1}\right)$, devem ter sido exportados cerca de $215 \mathrm{~kg} \mathrm{ha}^{-1}$ de $\mathrm{K}$ que precisariam ser repostos via adubação orgânica.

Também a análise química das folhas poderia dar subsídios para embasar esta hipótese, caso o teor de $\mathrm{K}$ na testemunha estivesse dentro da faixa considerada ideal para o tomateiro. Marouelli \& Silva (2002) recomendam, para uma boa produção, que o nível de $\mathrm{K}$ nas folhas do tomateiro, no início do florescimento, fique na faixa de 30 a $50 \mathrm{~g} \mathrm{~kg}^{-1}$ de matéria seca. Por outro lado, os teores deste nutriente nos tratamentos com as maiores doses devem ter sido elevados, visto que a planta absorve e acumula este nutriente em grande quantidade, mesmo não necessitando, o que caracteriza a denominada absorção de luxo, o que foi relatado em beterraba por Magro et al. (2015). Estes autores observaram que a aplicação de potássio em cobertura não afetou a produção de beterraba, porém aumentou o teor deste nutriente nas folhas.

Destaca-se, também, que não é incomum se obter ausência de efeito com a adubação potássica em algumas hortaliças, conforme relatado por Godoy et al. (2012) e por Magro et al. (2015), que estudaram doses de K inorgânico (KCl). Nesta pesquisa, foram estudadas fontes orgânicas, pouco estudadas. Espera-se que a liberação de $\mathrm{K}$ seja relativamente rápida (Magro et al., 2010; Souza \& Resende, 2012), mas não foram encontradas pesquisas com estas fontes que comprovem a eficiência na liberação do nutriente e efeito sobre a produtividade.

Outra hipótese para a ausência de diferença estatística entre os tratamentos é que o excesso de Ca na área do experimento pode ter afetado a resposta aos tratamentos com adubação potássica. Na área do experimento o teor de Ca no solo, 0 a $20 \mathrm{~cm}$, se

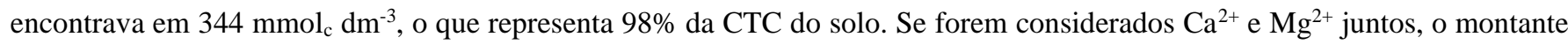
chegava a $366 \mathrm{mmol}_{\mathrm{c}} \mathrm{dm}^{-3}, 122$ vezes maior que o nível de $\mathrm{K}^{+}$(de apenas $3 \mathrm{mmol}_{\mathrm{c}} \mathrm{dm}^{-3}$ ), muito longe da relação de 9:3:1, para $\mathrm{Ca}, \mathrm{Mg}$ e $\mathrm{K}$ respectivamente, utilizado por muito produtores e técnicos.

Existe uma competição pelos sítios de ligação na CTC e os nutrientes possuem capacidades diferentes de se ligar ao solo. A relação dos íons $\mathrm{Ca}^{2+}, \mathrm{Mg}^{2+}$ e $\mathrm{K}^{+}$na solução do solo pode influenciar a resposta das plantas nas adubações desses elementos. O potássio é o segundo cátion com menor capacidade de se ligar a CTC, perdendo apenas para o sódio (Raij, 2017).

Essa incapacidade de lutar por um espaço na CTC em nível de igualdade com Ca e Mg pode fazer com que as adubações potássicas tenham menor efeito residual em solos com alto teor dessas bases. Isto foi relatado por Oliveira et al. (2001), que estudando os efeitos da relação do potássio, cálcio e magnésio na cultura da soja, observaram menor disponibilidade de $\mathrm{K}^{+}$no solo quando a relação $(\mathrm{Ca}+\mathrm{Mg}) / \mathrm{K}$ é superior a 36. Nolla et al. (2020) também relataram redução nos teores de potássio em Latossolo Vermelho distrófico na ordem de 13\% quando realizadas calagens excessivas (3,4 e 4,4 ton.ha $\left.{ }^{-1}\right)$. 
Esse desequilíbrio entre $\mathrm{Ca}$ e $\mathrm{K}$ poderia explicar porque mesmo em tratamentos com as maiores doses de $\mathrm{K}_{2} \mathrm{O}$ (700 kg ha1) (T11, T12, T13 e T14) não apresentaram sintomas de toxidez nas plantas e ainda mostraram frutos com "Golden Spot", ou "pinta dourada", sintoma relacionado a relação $\mathrm{Ca} / \mathrm{K}$ muito alta (Yara Brasil, 2020b).

Além da produção de frutos, também não houve diferença para massa média de fruto (média de 99,2 g), porcentagem de frutos ocos $(42,2 \%)$, pouco ocos $(23,5 \%)$ e cheios $(34,3 \%)$ (Tabelas 1 e 2). Uma das causas para o aparecimento de frutos ocos é a deficiência de potássio (Sousa, 2011). Como não foram feitas análises dos teores de $\mathrm{K}$ nos frutos, não se pode dizer que houve deficiência, mas, aparentemente, a utilização destas fontes não afetou essa importante característica qualitativa. Frutos ocos muitas vezes não apresentam formato normal e apresentam menor valor na comercialização, inclusive no mercado de produtos orgânicos.

De acordo com Sousa (2011), a deficiência de potássio, além de afetar a produção, também afeta a qualidade. Em tomateiro, a deficiência pode ser observada inicialmente nas folhas mais velhas, onde surge uma clorose internerval e posteriormente ocorre a morte das bordas e ponta das folhas (Incaper, 2010). Isto não foi observado na presente pesquisa, mesmo na testemunha. Portanto, provavelmente não houve deficiência de potássio e a ocorrência de frutos ocos e pouco ocos deve ter outra causa, talvez genética, tendo em vista que o híbrido utilizado tem se mostrado mais suscetível a esta anormalidade entre os híbridos utilizados na propriedade.

Outra hipótese que poderia explicar a alta incidência de frutos ocos está na polinização ineficiente das flores. Provavelmente relacionada a uma deficiência de Boro (B) causada pelo baixo teor do elemento no solo potencializado pelo elevado $\mathrm{pH}$ da área e a alta temperatura do ar no período do ensaio.

O elemento B é muito importante para o crescimento e desenvolvimento das plantas de tomate. Para Castellanos (2009), o micronutriente participa de maneira relevante no processo de divisão e alongamento celular, especialmente das células do tubo polínico. Desempenha função estrutural na parede celular vegetal, auxilia na permeabilidade das membranas celulares (Minami \& Mello, 2017) e participa da formação de hormônios e do DNA e RNA das plantas (Yara Brasil, 2020a).

Aplicações do micronutriente podem proporcionar aumento na produtividade do tomateiro, devido a produção de frutos mais pesados e em maior quantidade. Zamban (2014) relata em ensaio com tomate tipo italiano, híbrido Netuno, submetido a adubação de base com $4 \mathrm{~g} \mathrm{cova}^{-1} \mathrm{de} \mathrm{B}$, um aumento de produtividade de $44 \mathrm{t} \mathrm{ha}^{-1}$ para $50 \mathrm{t} \mathrm{ha}^{-1}$.

Segundo Mouco (2004), em condição de escassez de B a polinização é reduzida, os grãos de pólen perdem qualidade e a formação do tubo polínico é afetada. Fatores que, entre outros, podem contribuir para ocorrência de frutos ocos (Minami \& Mello, 2017).

$\mathrm{Na}$ área experimental, o teor de $\mathrm{B}$ no momento do ensaio era de $0,4 \mathrm{mg} \mathrm{dm}^{-3} \mathrm{e} 0,3 \mathrm{mg} \mathrm{dm}^{-3}$, para camada de 0 a 20 e 20 a $40 \mathrm{~cm}$, respectivamente. Esse nível de B no solo se encontra próximo ao limite inferior da faixa de 0,31 a 0,60 $\mathrm{mg} \mathrm{dm}^{-3}$, considerada mediana por Trani et al. (2015). Outro dado importante, determinado previamente em análise de solo, foi o $\mathrm{pH}$ do solo da área, que se encontrava próximo da neutralidade (6,6 e 6,9 nas camadas de 0 a 20 e 20 a $40 \mathrm{~cm}$, respectivamente). Em solos com pH neutros e básicos, iguais ou superiores a sete, o $\mathrm{B}$ passa da forma de ácido bórico $\left(\mathrm{H}_{3} \mathrm{BO}_{3}\right)$ para a forma aniônica $\left(\mathrm{H}_{2} \mathrm{BO}_{3}^{-}\right)$forma repelida pela CTC do solo e, por esse fato, facilmente lixiviada (Raij, 2017).

As plantas do experimento não apresentaram sintomas característicos de deficiência de B, como o sintoma, conhecido popularmente entre os produtores como "cara de gato", uma profunda rachadura que deixa o tecido placentário do fruto a mostra (Clemente \& Boiteux; 2012). Todavia, pode ter ocorrido "fome oculta" de B na área, que seria a falta do elemento em nível adequado, mas não o suficiente para ocorrência de sintomas mais claros de deficiência (Malavolta et al., 1997), afetando apenas parcialmente a viabilidade dos grãos de pólen e levando a ocorrência de frutos não totalmente cheios. 
As altas médias de temperatura do período também podem ter contribuído para elevada incidência de frutos ocos. Segundo Silva et al. (2006), temperaturas noturnas elevadas, da ordem de $32^{\circ} \mathrm{C}$ ou mais, contribuem para formação de frutos ocos.

Portanto, considerando-se todos esses fatores, a ausência de diferença significativa para frutos cheios deve ter ocorrido porque estes fatores (híbrido mais suscetível a ocorrência de frutos ocos, $\mathrm{pH}$ elevado com possível redução na disponibilidade de B e elevadas temperaturas) foram comuns a toda área experimental.

Ao contrário do sistema convencional em que são utilizados adubos solúveis, que disponibilizam nutrientes prontamente às plantas, como o cloreto de potássio, em sistemas orgânicos a principal fonte de nutrientes é pela mineralização da matéria orgânica (Souza \& Resende, 2012; Monsalve et al., 2017). Considerando-se que na propriedade onde foi realizado o estudo o aporte de matéria orgânica é feito antes de cada safra, pode-se dizer que o solo apresenta uma reserva muito grande de nutrientes para ser liberado e absorvido pelas plantas, resultando em bons níveis de produtividade mesmo se em uma safra não forem colocadas fontes suficientes para suprir as necessidades das plantas. Claro que nesta situação o solo vai ficar mais pobre e vai perder parte de suas reservas. Existem pesquisas que têm mostrado a importância do efeito residual da adubação orgânica em uma safra sobre a produtividade da próxima safra (Lanna et al., 2018). Estes autores relataram que em solos pouco férteis o efeito residual é mais pronunciado, enquanto que em solos ricos em matéria orgânica o efeito residual de uma safra sobre a próxima é menor, tendo em vista que o solo já tem uma reserva. Provavelmente esta é a explicação para a ausência de diferenças na produtividade, o solo já tinha uma grande reserva e pouco respondeu a adubação realizada.

Quanto ao teor de sólidos solúveis totais, também não houve diferença entre os tratamentos, com média de $2,9^{\circ}$ Brix (Tabelas 1 e 2). O valor pode ser considerado relativamente baixo em comparação a outros autores. Martins et al. (2018) relataram valores entre 4,76 a 4,90 ${ }^{\circ}$ Brix, com o híbrido Paron, enquanto Takahashi \& Cardoso (2014) obtiveram teor de 7,1 ${ }^{\circ}$ Brix para o mini tomate 'Sweet Grape' em sistema orgânico, Abrahão et al. (2014) relataram teor de 7,4 $4^{\circ}$ Brix para o híbrido de mini tomate 'Sweet Million', e por Candian et al. (2017) que também obtiveram teor de 7,4 $4^{\circ}$ Brix para frutos do mini tomate 'Coco' em sistema orgânico.

Silva et al. (1994) afirmam que o teor de sólidos solúveis no fruto, além de ser uma característica genética da cultivar, é influenciado por fatores externos como o local, temperatura, época de colheita, o estresse, a idade da planta e as práticas culturais. Todos os autores citados avaliaram apenas frutos bem maduros, quando o teor de sólidos solúveis é maior que em frutos iniciando a mudança de cor, que foi o estádio em que os frutos foram colhidos na presente pesquisa. Além disso, a maioria dos autores citados trabalharam com mini tomates que apresentam, em média, maior teor de sólidos solúveis. No entanto, apesar de alguns autores relatarem influência da adubação potássica nesta característica (Chitarra \& Chitarra, 2005), não houve diferença entre as doses, fontes e modos de aplicação.

O teor de sólidos solúveis apresenta grande importância para o consumidor, pois elevados teores implicam em frutos mais adocicados. No final da fase de maturação, os sólidos solúveis acumulam-se, constituídos por aproximadamente $65 \%$ de açúcares, que representam a percentagem (em massa) de sólidos que se encontram dissolvidos na água dos frutos (Alvarenga, 2013; Chitarra \& Chitarra, 2005).

\section{Considerações Finais}

As fontes comerciais de potássio disponíveis para o mercado orgânico, atualmente, ainda são poucas. Existe a urgente necessidade de mais insumos de qualidade e eficácia comprovada para esse nicho do agronegócio.

Os resultados desta pesquisa mostram que, talvez, em locais onde o aporte de material orgânico é realizado a cada safra, como ocorre na maioria das propriedades certificadas, talvez não sejam necessárias aplicações em doses tão elevadas de fontes potássicas certificadas, reduzindo o custo de produção. Destaque-se, ainda, que na propriedade o cultivo de tomate é realizado 
em ambiente protegido, onde o acúmulo de potássio aplicado em excesso é maior, pois não ocorre lixiviação devido a não ocorrência de precipitação dentre destes ambientes.

Mais estudos de solubilidade e efeito residual no solo de fontes comerciais de potássio e resíduos orgânicos, para o cultivo orgânico, são fundamentais para a tomada de decisão do produtor, uma vez que adubos potássicos certificados têm custo elevado e, em muitos casos, poderiam ser substituídos por resíduos orgânicos mais baratos sem alterar a resposta das culturas. Portanto, sugere-se que sejam realizadas pesquisas com novas fontes de potássio aceitas para o sistema orgânico para se poder fazer recomendações que sejam técnica e economicamente viáveis aos produtores de tomate no sistema orgânico. Além disto, há a necessidade de se realizar outras avaliações, tais como análise química das plantas e do solo ao final do ciclo o que demanda maiores recursos financeiros.

\section{Referências}

Abrahão, C.; Villas Boas R. L. \& Bull L. T. (2014). Relação K:Ca:Mg na solução nutritiva para a produção de minitomate cultivado em substrato. Irriga, 19(2), 214-224.

Almeida, L. G. (2017). Nutrição do tomateiro cultivado em sistema orgânico com a aplicação de biofertilizantes através da Fertirrigação. (Dissertação de Mestrado). Universidade Estadual Paulista "Júlio de Mesquita Filho", Botucatu, Brasil.

Alvarenga, M. A. R. (2013). Tomate: produção em campo, em casa-de-vegetação e em hidroponia. Lavras: UFLA.

Arruda, J. A.; Azevedo, T. A. O.; Freire, J. L. O. \& Bandeira, L. B. (2016). Uso da cinza de biomassa na agricultura: efeitos sobre atributos do solo e resposta das culturas. Revista Principia, 30, 1-13.

Candian, J. S.; Martins, B. N. M.; Cardoso, A. I. I.; Evangelista, R. M. \& Fujita, E. (2017). Conduction types of stem in production and quality of mini tomato in organic management. Bragantia, 76(2), 238-245.

Castellanos, Z. J. (ed). (2009). Manual de producción de tomate en invernadero. Celaya: Intagri, S.C.

Chitarra, A. B. \& Chitarra, M. I. F. (2005). Pós-colheita de frutas e hortaliças: fisiologia e manuseio. Lavras: UFLA.

Clemente, F. M. V. T. \& Boiteux, L. S. (2012). Produção de tomate para processamento industrial. Brasília: Embrapa, 2012.

Ernani, P. R.; Almeida, J. A. \& Santos, F. C. (2007). Potássio. In: Novais, R. F. (Org). Fertilidade do Solo. Sociedade Brasileira de Ciência do Solo.

Faostat. (2019). Área colhida, produtividade e produção nos principais países produtores de tomate. Food and Agriculture Organization of the United Nations. Recuperado de: http://faostat.fao.org.

Fernandes, L. B.; Santos, A. P.; Costa, C. L. L; Oliveira, F. A. \& Goes, G. B. (2011). Influência da torta de mamona nas características químicas do solo. Revista Verde, 6(3), 156-159.

Ferreira, A. (2011a). Influência da borra de café no crescimento e nas propriedades químicas e biológicas de plantas de alface (Lactuca sativa L.). (Dissertação de Mestrado). Instituto Politécnico de Bragança, Escola Superior Agrária. Bragança, Portugal.

Ferreira, D. F. (2011b). Sisvar: a computer statistic analysis system. Ciência e Agrotecnologia, 35, 1039-1042.

Godoy, A. R.; Salata, A. C.; Kano, C.; Higuti, A.; Cardoso, A. I. I. \& Evangelista, R. M. (2012). Produção e qualidade de couve-flor com diferentes doses de potássio em cobertura. Scientia Agrária Paranaensis, 11(2), 33-42.

Incaper. (2010). Tomate. Vitória: Instituto Capixaba de Pesquisa, Assistência Técnica e Extensão Rural.

Lanna, N. B. L.; Silva, P. N. L.; Colombari, L. F.; Corrêa, C. V. \& Cardoso, A. I. I. (2018). Residual effect of organic fertilization on radish production. Horticultura Brasileira, 36(1), 47-53.

Lira, V. M. C. (2018). Produção orgânica no Brasil. Ministério da Agricultura. Recuperado de: www.organicsnet.com.br.

Magro, F. O.; Arruda, N.; Casa, J.; Salata, A. C.; Cardoso, A. I. I. \& Fernandes, D. M. (2010). Organic compost in broccoli seed yield and quality. Ciência e Agrotecnologia, 34, 596-602.

Magro, F. O.; Silva, E. G.; Takata, W. H. S.; Cardoso, A. I. I.; Fernandes, D. M. \& Evangelista, R. M. (2015). Organic compost and potassium top dressing fertilization on production and quality of beetroot. Australian Journal of Crop Science, 9, 962-967.

Malavolta, E.; Vitti, G. C. \& Oliveira, S. A. (1997). Avaliação do estado nutricional das plantas: princípios e aplicações. (2. ed.) Piracicaba: Potafos.

Marouelli, W. A. \& Silva, W. L. C. (2002). Tomateiro para processamento industrial: Irrrigação e Fertirrigação por gotejamento. Brasília: Embrapa.

Martins, V. F. R. (2017). Caraterização morfológica e química de acessos de tomate (Solanum lycopersicum L.) conservados no Banco Português de Germoplasma Vegetal. (Dissertação de Mestrado). Instituto Politécnico de Braga, Braga, Portugal. 
Minami, K. \& Mello, S. C. (2017). Fisiologia e nutrição do tomateiro. (1 ed.) Curitiba: Senar.

Monsalve, O. I.; Gutiérrez, J. S. \& Cardona, W. A. (2017). Factores que intervienen em el processo de mineralización de nitrógeno cuando son aplicadas en meiendas orgânicas al suelo. Revista Colombiana de Ciências Horticolas, 11, 200-209.

Mouco, M. A. C. (Ed.). (2004). Cultivo da mangueira. Petrolina: Embrapa Semi-Árido. (Embrapa Semi-Árido. Sistemas de Produção, 2).

Mueller, S.; Wamser, A. F. \& Suzuki, A. (2015). Produtividade de tomate em função da adubação potássica. Agropecuária Catarinense, 28(1), 92-96.

Nolla, A.; Alves, E. O. S.; Silva, T. G. \& Bordin, A. V. (2020). Correção da acidez e disponibilização de fósforo e potássio em latossolo vermelho distrófico típico submetido à calagem incorporada e superficial. Brazilian Journal of Animal and Environmental Research, 3(3), $2478-2487$.

Oliveira, F. A.; Carmello, Q. A. C. \& Mascarenhas, H. A. A. (2001). Disponibilidade de potássio e suas relações com cálcio e magnésio em soja cultivada em casa-de-vegetação. Scientia Agricola, 58(2), 329-335.

Partelli, F. L.; Gontijo, I.; Espindula, M. C. \& Dias, J. R. M. (2014). Adubação Parcelada - Revista Cultivar. Recuperado de: https://www.grupocultivar.com.br/artigos/adubacao-parcelada.

Paulifertil. (2021). Sulfato de Potássio Paulivida. Recuperado de: http://paulifertil.com.br/novo/projects-archive/sulfato-de-potassio.

Raij, B. V. (2017). Fertilidade do Solo e Manejo de Nutrientes. (2 ed.) Piracicaba: International Plant Nutrition Institute.

Ramalho, A. M. \& Pires, A. M. M. (2010). Fontes alternativas de potássio em agricultura orgânica. IAC. Recuperado de: http://www.iac.sp.gov.br/areadoinstituto/pibic/anais/2010/ Artigos/RE10401.pdf.

Silva, J. B. C.; Giordano, L. B.; Boiteux, L. S.; Lopes, C. A.; França, F. H.; Santos, J. R. M.; Furumoto, O.; Fontes, R. R.; Marouelli, W. A.; Nascimento, W. M.; Silva, W. L. C. \& Pereira, W. (1994). Cultivo do tomate (Lycopersicon esculentum Mill.) para industrialização. Brasília: Embrapa-CNPH.

Silva, J. B. C.; Giordano, L. B.; Furumoto, O.; Boiteux, L. S.; França, F. H.; Villas Bôas, G. L.; Castelo Branco, M.; Medeiros, M. A.; Marouelli, W.; Silva, W. L. C.; Lopes, C. A.; Avila, A. C.; Nascimento, W. M. \& Pereira, W. (2006). Cultivo de Tomate para Industrialização. (2 ed.) Brasília: Embrapa Hortaliças. Sousa, V. F; Marouelli, W. A; Coelho, E. F; Pinto, J. M; Coelho Filho, M. A. (2011). Irrigação e fertirrigação em fruteiras e hortaliças. Embrapa Informação Tecnológica. Brasília, Brasil.

Souza, J. \& Resende, P. (2012). Manual de Horticultura orgânica. Viçosa: Aprenda Fácil.

Sqm-Vitas. (2021). Sulfato de Potássio Allganic. Recuperado de: https://sqm-vitas.com.br/produto/allganic-potassium.

Takahashi, K. \& Cardoso, A. I. I. (2015). Produção e qualidade de mini tomate em sistema orgânico com dois tipos de condução de hastes e poda apical. Horticultura Brasileira, 33, 515-520.

Trani, P. E.; Kariya, E. A.; Hanai, S. M.; Anbo, R. H.; Bassetto Júnior, O. B.; Purquerio, L. F. V. \& Trani, A. L. (2015). Calagem e adubação do tomate de mesa. (n. 215). Campinas: Instituto Agronômico - IAC.

Vieira, A. \& Jorge, L. (2002). Influência da adubação potássica na produtividade e qualidade do tomate para consumo em fresco (Lycopersicon esculentum Mill.) cultivado ao ar livre. Recuperado de: http://hdl.handle.net/10198/3370.

Yara Brasil. (2020a). Função do Boro na Produção de Tomate. Recuperado de: https://www.yarabrasil.com.br/conteudo-agronomico/blog/funcao-do-boro-naproduca o-de-tomate.

Yara Brasil. (2020b). Prevenção de Pontos Amarelos (Gold Spot) no Tomate. Recuperado de: https://www.yarabrasil.com.br/conteudoagronomico/blog/prevencao-de-pontos-amarelos-gold-spot-no-tomate.

Zamban, D. T. (2014). Fenologia e efeito da utilização de doses de boro e cálcio sobre a produção de tomate italiano em duas épocas de cultivo. (Dissertação de Mestrado). Universidade Federal de Santa Maria, Santa Maria, Brasil. 